\title{
PENGARUH KREDIBILITAS, INFORMATIF, DAN EMPATI SMS ADVERTISING TERHADAP INTENSITAS PEMBELIAN KONSUMEN DI JAKARTA
}

\author{
Sanny Ekawati ${ }^{1}$, Thea Herawaty ${ }^{2}$ \\ ${ }^{1}$ Jurusan Ekonomi Manajemen, Universitas Tarumangara Jakarta \\ Email: sannye@fe.untar.ac.id \\ ${ }^{2}$ Jurusan Ekonomi Manajemen, Universitas Tarumanagara Jakarta \\ Email: theah@fe.untar.ac.id
}

\begin{abstract}
ABSTRAK
Penelitian ini bertujuan untuk mengetahui pengaruh kredibilitas, infomatif dan empati dalam menerima SMS advertising terhadap intensitas pembelian konsumen. Tehnik pemilihan sampel menggunakan purposive sampling sebanyak 93 responden yang tersebar di wilayah Jakarta. Selanjutnya data akan diolah menggunakan PLS (Partial Least Square). Hasil dari penelitian menyatakan bahwa variabel kredibilitas iklan SMS berpengaruh terhadap intensitas pembelian, variabel informatif iklan SMS berpengaruh terhadap intensitas pembelian, variable empati iklan SMS berpengaruh terhadap intensitas pembelian, dan semua variabel independen (kredibilitas, informastif, dan empati) iklan SMS berpengaruh secara simultan terhadap intensitas pembelian konsumen.
\end{abstract}

Kata kunci: kredibilitas, infomatif, empati, intensi pembelian, PLS

\section{PENDAHULUAN}

\section{Latar Belakang}

Perkembangan teknologi khususnya telepon selular sebagai alat komunikasi jarak jauh mengalami kemajuan cukup pesat selain internet. Dari tahun ke tahun penggunaan telepon selular mengalami peningkatan yang sangat pesat sebagai alat komunikasi. Di Indonesia sendiri, SMS diperhitungkan sebagai media beriklan sebab fakta menunjukkan bahwa puluhan juta pengguna layanan jaringan komunikasi seluler semuanya berkomunikasi melalui SMS. Fakta mengenai traffic SMS ini menunjukkan adanya tingkat kesadaran konsumen di Indonesia yang tinggi untuk penggunaan $S M S$, sekaligus menjadi alasan yang kuat mengapa perusahaan di Indonesia kini semakin giat memanfaatkan mobile advertising berbasis SMS. SMS adalah sebuah media iklan yang ideal untuk menjangkau konsumen muda dan sangat tergantung dari kredibilitas, informasi maupun empati (Scharl, Dickinger dan Murphy, 2005). Scharl et al.. (2005) mendefinisikan mobile marketing sebagai penggunaan media nirkabel untuk menyediakan pelanggan dengan informasi individual tentang produk, jasa, dan ide pada setiap waktu dan lokasi, yang menguntungkan semua pemangku kepentingan. SMS advertising didefinisikan sebagai "menggunakan sms, untuk dikirimkan ke telepon genggam konsumen, untuk menyediakan konsumen informasi waktu dan tempat yang mempromosikan barang, jasa, dan ide, sehingga menghasilkan nilai bagi semua penerima informasi." (Kavassalis, 2003). Kredibilitas didefinisikan sebagai "Sejauh mana konsumen merasakan klaim tentang merek didalam sebuah iklan untuk berkata jujur dan terpercaya." (Mackenzie \&Lutz, 1989).Sedangkan menurut Varey (2002), kredibilitas dapat didefinisikan sebagai sejauh mana konsumen merasakan sebuah perusahaan dapat menjadi sumber informasi dipercaya, berdasarkan keahlian yang relevan cukup. Oh \& Xu (2003) mengungkapkan keinformatifan mengacu pada kemampuan suatu pesan yang efektif dan dapat memberikan suatu informasi yang relevan. Dalam pesan komersial, keinformatifan adalah kemampuan iklan untuk menyampaikan informasi yang bermanfaat (Daugherty, Logan, Chu, \& Huang, 2008) dan ini ditunjukkan oleh sejauh mana penyedia web menawarkan informasi bermanfaat dan praktis (Okazaki, 2005). Empati adalah elemen interaksi langsung tanpa bertatap muka yang berhubungan 
dengan penyediaan perhatian peduli dan individual kepada pelanggan seperti komunikasi melalui e-mail. Hal ini termasuk memberikan perhatian individual kepada keprihatinan dan permintaan pelanggan bukan balasan otomatis generik (Nusair \& Kandampully, 2008). Peter dan Olson (2002) mendefinisikan purchase intention adalah "based on a consumer attitude toward buying brand". Artinya, intensi pembelian berdasarkan pada sikap konsumen yang mengarahkan pembelian merek.

\section{Rumusan Masalah}

SMS advertising melalui mobilephone terus berkembang dan tidak dapat dicegah. Untuk itu beberapa masalah penelitian akan dikaji dalam penelitian ini adalah apakah terdapat pengaruh credibility terhadap purchase intention? Apakah terdapat pengaruh informativeness terhadap purchase intention? Apakah terdapat pengaruh empathy terhadap purchase intention?Apakah terdapat pengaruh credibility, informativeness, dan empathy SMS advertising terhadap purchase intention secara simultan?

\section{METODE PENELITIAN}

\section{Tehnik Pemilihan Sampel}

Penelitian ini menggunakan sampel dengan teknik purposive sampling, dimana sampel yang dipilih memiliki kriteria berumur lebih dari 18 tahun, memiliki ponsel 2 tahun terakhir, pernah menerima iklan $S M S$ dalam satu bulan terakhir saat pengambilan data. Sampel yang diperoleh sebanyak 93 responden, yang tersebar di wilayah Jakarta.

\section{Tehnik Pengumpulan Data}

Penelitian ini dilakukan dengan memberikan sejumlah pertanyaan-pertanyaan dalam bentuk angket kepada responden yang terpilih sebagai sampel. Format angket tersebut menggunakan skala Likert yang dimodifikasi bergerak dari 1 sampai 7 yaitu Sangat tidak setuju sampai sangat setuju sekali.

\section{Tehnik Analisis Data}

Tabel 1. variabel dan indikator penelitian

\begin{tabular}{|l|l|}
\hline \multicolumn{1}{|c|}{ Variabel } & \multicolumn{1}{|c|}{ Indikator } \\
\hline \multirow{4}{*}{ Credibility } & Dinamis \\
\cline { 2 - 2 } & Kebenaran \\
\cline { 2 - 2 } & Kejujuran \\
\cline { 2 - 2 } & Dapat Diandalkan \\
\cline { 2 - 2 } & Terpercaya \\
\hline \multirow{4}{*}{ Informativeness } & Alternatif \\
\cline { 2 - 2 } & Kepuasan \\
\cline { 2 - 2 } & Detil \\
\cline { 2 - 2 } & Relevan \\
\cline { 2 - 2 } & Membantu \\
\hline \multirow{5}{*}{ Empathy } & Kepedulian \\
\hline & Kecepatan Tanggap \\
\cline { 2 - 2 } & Keramahan \\
\cline { 2 - 2 } & Tanggung Jawab \\
\cline { 2 - 2 } & Kesabaran \\
\hline
\end{tabular}


Purchase Intention

\begin{tabular}{|l|} 
Kesediaan \\
\hline Berencana Untuk Mencoba \\
\hline Pembelian Kembali \\
\hline Merekomendasikan ke Orang Lain \\
\hline Pemberian Review Positif \\
\hline Berhubungan Dengan Perusahaan \\
\hline
\end{tabular}

Sumber: Tsang, Ho dan Ling (2004)

Dalam penelitian ini analisis data menggunakan metode Partial Least Square (PLS). Ghozali (2011) menyimpulkan bahwa PLS adalah sebuah pendekatan alternatif yang bergeser dari pendekatan SEM berbasis covariance menjadi berbasis variance.

\section{HASIL DAN PEMBAHASAN}

Deskripsi Subyek Penelitian

Subyek penelitian ini sebanyak 93 responden dan hasil penilaian dari kuesioner menunjukkan bahwa jenis kelamin responden yang memberikan penilaian dari kuesioner sebagian besar adalah wanita yaitu sebesar $68.8 \%$ penerima Iklan SMS. Sedangkan dilihat dari komposisi berdasarkan usia. Dari total 93 penerima iklan $S M S$ yang memberikan jawaban terbanyak berada pada usia 26 sampai 40 tahun yaitu sebesar $41.94 \%$. Penerima iklan SMS yang memberikan penilaian dikelompokkan sesuai dengan pendidikan terakhir. Responden yang berpendidikan sarjana yang terbanyak yaitu sebesar $38.7 \%$.

\section{Deskripsi Obyek Penelitian}

Deskripsi obyek penelitian berisi tanggapan responden atas kelompok pernyataan yang terdiri atas: Credibility, Informativeness, Empathy dan purchase intention dari iklan SMS. Statistik deskriptif berfungsi untuk mengetahui tentang karakteristik sampel yang digunakan secara lebih rinci. Dengan menggunakan statistik deskriptif menjabarkan mengenai jawaban responden dalam bentuk nilai rata-rata dan standar deviasi dari masing - masing variabel.

Tabel 2. Descriptive Statistics

\begin{tabular}{lr|r|r|r|r} 
& $N$ & \multicolumn{1}{|c|}{ Minimum } & Maximum & \multicolumn{1}{c|}{ Mean } & Std. Deviation \\
\hline CR1 & 92 & 2 & 7 & 5.70 & .946 \\
\hline CR2 & 92 & 3 & 7 & 5.47 & .818 \\
\hline CR3 & 92 & 3 & 7 & 5.77 & .962 \\
\hline CR4 & 92 & 2 & 7 & 5.17 & .720 \\
\hline CR5 & 92 & 4 & 7 & 5.45 & .843 \\
\hline IF1 & 92 & 4 & 7 & 5.28 & .803 \\
\hline IF2 & 92 & 3 & 7 & 5.25 & .779 \\
\hline IF3 & 92 & 3 & 7 & 5.02 & .937 \\
\hline IF4 & 92 & 3 & 7 & 5.39 & .972 \\
\hline IF5 & 92 & 3 & 7 & 5.25 & .807 \\
\hline EM1 & 92 & 4 & 7 & 5.26 & .591 \\
\hline EM2 & 92 & 4 & 7 & 5.45 & .717 \\
\hline EM3 & 92 & 4 & 7 & 5.55 & .618 \\
\hline
\end{tabular}




\begin{tabular}{l|r|r|r|r|r}
\hline EM4 & 92 & 4 & 7 & 5.59 & .632 \\
\hline EM5 & 92 & 4 & 7 & 5.39 & .695 \\
\hline Valid N (listwise) & 92 & & & & \\
\hline
\end{tabular}

\section{Pengujian Dengan PLS}

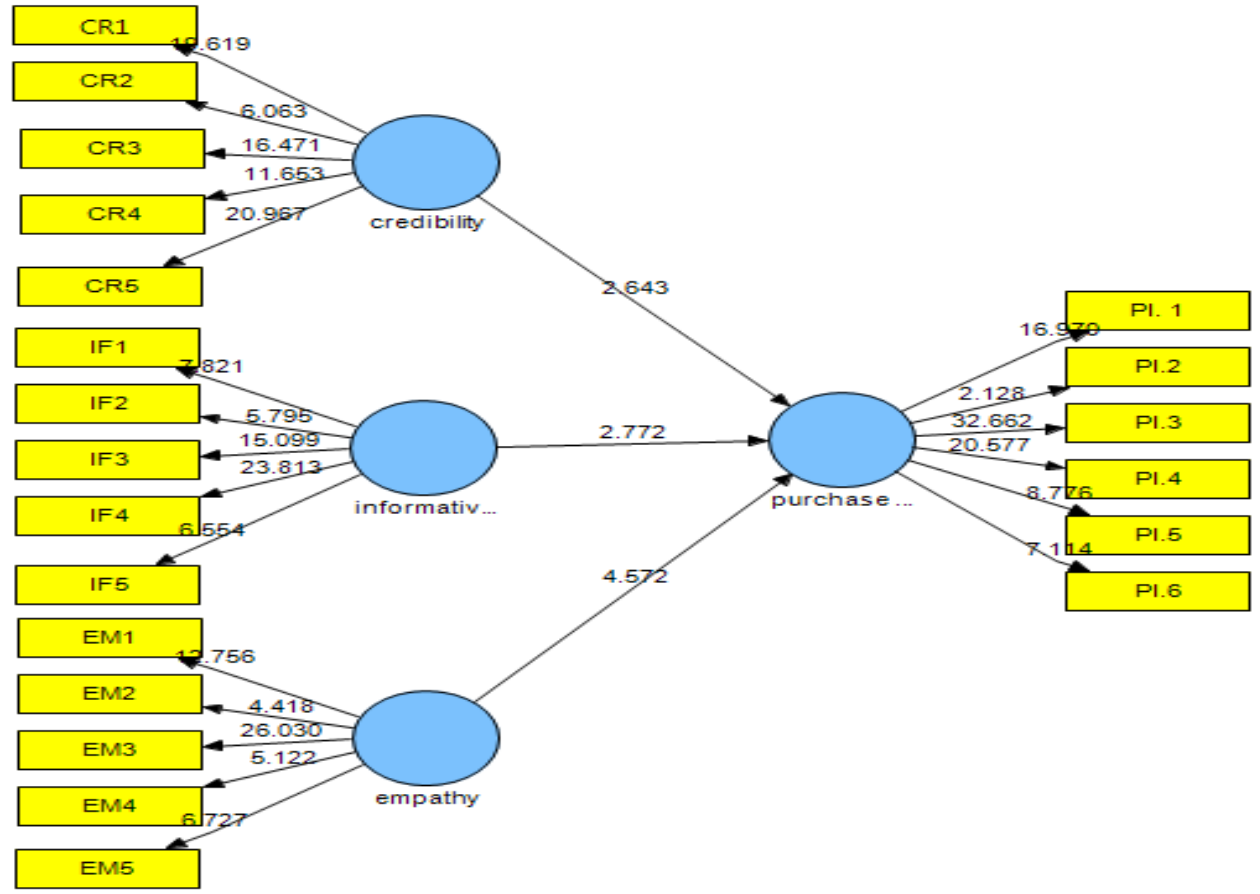

Gambar 1. Nilai t

\section{Pengujian Hipotesis}

\section{Hipotesis 1:}

Credibility berpengaruh terhadap Purchase Intention.

Melalui hasil analisis menunjukkan :

\begin{tabular}{|c|c|}
\hline Path & t-value \\
\hline Credibility berpengaruh terhadap Purchase Intention & $2.643398>1,96$ \\
\hline
\end{tabular}

Hasil analisis data diketahui bahwa nilai $\mathrm{t}=2.64$. Karena nilai $\mathrm{t}>1,96$ maka $\mathrm{H}_{0}$ ditolak dan $\mathrm{H}_{1}$ diterima, yang berarti Credibility berpengaruh signifikan terhadap Purchase Intention, (Aritonang, 2007). Dengan demikian dapat diambil kesimpulan bahwa Credibility dapat digunakan untuk memprediksi Purchase Intention.

\section{Hipotesis 2:}

Informativeness berpengaruh terhadap Purchase Intention.

Berdasarkan hasil analisis didapatkan hasil: 


\begin{tabular}{|c|c|}
\hline Path & $t$-value \\
\hline $\begin{array}{l}\text { Informativeness berpengaruh terhadap Purchase } \\
\text { Intention }\end{array}$ & $2.77>1,96$ \\
\hline
\end{tabular}

Hasil analisis data diketahui bahwa nilai $\mathrm{t}=2.77$. Karena nilai $\mathrm{t}>1,96$ maka $\mathrm{H}_{0}$ ditolak dan $\mathrm{H}_{2}$ diterima, yang berarti Informativeness berpengaruh signifikan terhadap Purchase Intention, (Aritonang, 2007). Dengan demikian dapat diambil kesimpulan Informativeness dapat digunakan untuk memprediksi Purchase Intention.

\section{Hipotesis 3:}

Empathy berpengaruh terhadap Purchase Intention.

Berdasarkan hasil analisis didapatkan hasil:

\begin{tabular}{|l|c|}
\hline \multicolumn{1}{|c|}{ Path } & t-value \\
\hline Empathy berpengaruh terhadap Purchase Intention & $4.572281>1,96$ \\
\hline
\end{tabular}

Hasil analisis data diketahui bahwa nilai $\mathrm{t}=4.57$. Karena nilai $\mathrm{t}>1,96$ maka $\mathrm{H}_{0}$ ditolak dan $\mathrm{H}_{3}$ diterima, yang berarti Empati berpengaruh signifikan terhadap Purchase Intention, (Aritonang, 2007) Dengan demikian dapat diambil kesimpulan bahwa Empati dapat digunakan untuk memprediksi Purchase Intention.

\section{Hipotesis 4:}

Credibility, informativeness, empathy berpengaruh terhadap Purchase Intention.

Berdasarkan hasil analisis didapatkan hasil:

\begin{tabular}{|c|c|}
\hline Path & $F ; p$ \\
\hline $\begin{array}{l}\text { Credibility, informativeness, empathy berpengaruh } \\
\text { terhadap Purchase Intention }\end{array}$ & $\begin{array}{c}28.178 ; 0.000< \\
0.05\end{array}$ \\
\hline
\end{tabular}

Hasil analisis data diketahui bahwa nilai $\mathrm{p}=0.000$. Karena nilai $\mathrm{p}<0.05 \mathrm{maka}_{0}$ ditolak dan $\mathrm{H}_{4}$ diterima, yang berarti credibility, informativeness, dan empathy berpengaruh signifikan terhadap purchase Intention. (Aritonang, 2007) dan (Malhotra, 2004). Dengan demikian dapat diambil kesimpulan bahwa credibility, informativeness, dan empathy dapat digunakan untuk memprediksi Purchase Intention. Besar pengaruh bersama credibility, informativeness, dan empathy terhadap Purchase Intention adalah 0.591 , artinya 59,1\%, sedangkan sisanya 40,9\% dipengaruhi faktor lain.

\section{KESIMPULAN DAN SARAN Kesimpuan}

Berdasarkan hasil analisis yang telah dilakukan maka diperoleh beberapa kesimpulan penelitian sebagai berikut:

1. Credibility berpengaruh signifikan terhadap Purchase Intention

2. Informativeness berpengaruh signifikan terhadap Purchase Intention 
3. Empathy berpengaruh signifikan terhadap Purchase Intention

4. Credibility, informativeness, dan empathy berpengaruh signifikan terhadap Purchase Intention

\section{Saran}

1. Dalam iklan SMS perlu memerhatikan credibility, informativeness, emphaty karena hal ini memengaruhi niat membeli konsumen.

2. Dari hasil penelitian konsumen lebih memusatkan perhatian pada variabel empati dalam penyampaian pesan SMS. Oleh karenanya dalam menyampaikan/ mengembangkan suatu pesan SMS , perusahaan harus dapat membangun empati konsumen.

3. Dapat dilakukan penelitian lanjutan dengan menambahkan variable lainnya, seperti kepercayaan, keamanan membeli suatu produk yang ditawarkan melalui iklan SMS.

\section{Ucapan Terima Kasih}

Kepada Direktur dan Staff DPPM Universitas Tarumanagara yang telah memberikan dukungan sehingga penelitian ini terselesaikan.

\section{REFERENSI}

Aritonang, Lerbin R. (2007). Riset Pemasaran. Bogor: Ghalia Indonesia

Daugherty, T., Logan, K., Chu, S.C., \& Huang, S.C. (2008). Understanding consumer perception of advertising: A theoretical framework of attitude and confidence. American Academy of Advertising. page:308-313.

Ghozali, Imam. (2011). Structural Equation Modelling : Metode Alternatif dengan Partial Least Square (PLS), edisi 3, Badan Penerbit Undip, Semarang.

Kavassalis P, Spyropoulou N, Drossos D, Mitrokostas E, Gikas G, Hatzistamatiou A. (2003). Mobile permission marketing: framing the market inquiry. Int. J. Elect. Commer. page: 55-79

Nusair, K. \& Kandampully, J. (2008). The antecedents of customer satisfaction with online travel services: a conceptual model. European Business Review.page: 4-19

Mackenzie S. B., Lutz R. J. (1989). An empirical examination of the structural antecedents of attitude towards the ad in an advertising

Malhotra, Naresh K. (2004). Marketing research. An Applied Orientation. $4^{\text {th }}$ Edition. New Jersey: Pearson Education

Oh, L.B. and Xu, H. (2003), Effects of multimedia on mobile consumer behavior: an empirical study of location-aware advertising.

Olson, dkk (1972), "The Effect of Brand Image and Product Knowledge on Purchase Intention Moderated by Price Discount", Journal of International Management Studies. page 121-132

Okazaki, S. (2005). Mobile advertising adoption by multinationals: Senior executives' initial responses. Internet Research. page: 160-180.

Tsang MM, Ho S, Liang T. (2004). Consumer attitudes toward mobileadvertising: an empirical study. Int. J. Elect. Commer. page: 65-78.

Varey, Richard J. (2002). Relationship Marketing: Dialogue and Networks in the E-Comerce Era. West Sussex: John Willey \& Sons, Inc. 